\title{
Qual o futuro do trabalho na agricultura francesa?*
}

\section{On the future of work in French agriculture}

\author{
EstelleDELÉAGE**
}

\section{RESUMO}

Este trabalho tem por objetivo analisar formas alternativas de organização do trabalho na "agricultura camponesa" em oposição à agricultura produtivista dominante. Tendo como referência camponeses organizados no Oeste de França, o texto mostra como a partir do desenvolvimento da agricultura ecológica - sustentável - os agricultores, através de suas atividades, passam a dar sentido às suas vidas. A noção moderna de trabalho é contemporânea ao desenvolvimento do capitalismo industrial. $O$ trabalho produtor de utilidade torna-se, assim, o centro da atividade econômica, atividade esta sobre a qual Adam Smith é um dos primeiros a construir uma teoria unificada. Desde que começa a se generalizar esta forma de trabalho, sobretudo nas sociedades onde o tempo compensado com salário se torna um dos maiores recursos da população, instaura-se por muito tempo (ou a partir de então) uma visão depreciativa do trabalho camponês. $\mathrm{O}$ arquétipo do trabalhador se torna o operário de usina e as atividades camponesas passam a ser vistas como o resíduo de uma forma arcaica do trabalho, estimulando-se o seu desaparecimento. Gostaríamos de propor uma outra forma de ver a questão a partir de alguns elementos de reflexão teórica, e dos primeiros resultados de uma enquête em andamento sobre a emergência no mundo agrícola de novas formas de organização do trabalho. Estas últimas contradizem as formas e as visões clássicas do trabalho camponês. Nossa hipótese é que elas prevêem a emergência de novas formas desalienadas do trabalho. Na realidade, em oposição aos agricultores "produtivistas" que, na maior parte, passam seu tempo "a ganhar sua vida", os agricultores "sustentáveis", objeto deste estudo, criam novas formas de atividade agrícola, que dão sentido a eles mesmos, em resposta às crises múltiplas do modelo produtivista dominante.

Palavras-chave: trabalho camponês, França.

\begin{abstract}
The objective of this paper is to analyze alternative forms of labor organization in "peasant agriculture", in opposition to the dominant productivist type of farming. Using organized peasants in Western France as our reference, the text shows how, through the development of sustainable ecological agriculture, farmers use their activities to give new meaning to their lives.

Key-words: peasant work, France.
\end{abstract}

* Texto publicado na Revue do Mauss. Étique et Economie: L'impossible le (re)mariage? Paris, n. 15, p. 382-397, jan./jun. 2000. Tradução: Ilze Justen Brandenburg e Alfio Brandenburg

** Doutora em Sociologia. <estelle.deleage@wanadoo.fr> 


\section{O esquecimento da questão do trabalho campesino}

É a partir dos anos 50, em uma situação particular de dependência alimentar, que na França uma nova política agrícola é colocada em prática no quadro da institucionalização do acordo entre o Estado e profissionais da agricultura representada então pelo sindicalismo agrícola modernizador (FNSEA e CNJA). ${ }^{1}$ Começando verdadeiramente a partir de 1960, sob o incentivo de Edgard Pisani, novo ministro da Agricultura, esta co-gestão vai estimular a integração da agricultura no sistema capitalista e sua subordinação ao ciclo industrial.

Assim, aquilo que era realizado um século antes na indústria realmente é colocado em prática na agricultura francesa. Neste contexto, uma parte da sociedade empreende uma erradicação simbólica e prática da economia camponesa, bem como de formas de trabalho associado. Esta questão só é tratada por raros economistas marxistas heterodoxos entre os quais Alexandre Tchayanov ${ }^{2}$ com relação aos agricultores familiares russos, e pela antropologia econômica (Sahlins, M. Polanyi, K. Godelier, M...). Na França, somente alguns trabalhos abordam esta questão da economia camponesa contemporâne a e da industrialização da agricultura (Per-net, $\mathrm{F}^{3}$ Alphandéry, P. Bitoun, P. Dupont, Y. etc.). ${ }^{4}$ A questão do trabalho camponês tem sido quase sempre tratada do ponto de vista da modernidade, considerando-se que a única via em direção a um maior progresso econômico e humano é a sua industrialização:

Agora, passado mais de um século, em nome da eficácia, da racionalização da economia ou do necessário desenvolvimento das forças produtivas, em resumo, em nome do progresso, os ideólogos da burguesia, também a maior parte dos marxistas, prevê "um mundo sem camponeses". Um mesmo ponto de vista norteia estes dois discursos: aquele da acumulação do capital. Um mesmo limite os contenta: aquele da grande indústria. Devemos então nos perguntar: não se trata de uma mesma concepção teórica do trabalhador? Não é isso que esconde a recusa do camponês? (DE CRISENOY, 1978, p. 13).

Dominique Méda, em sua obra a qual se tornou uma referência sobre a história do trabalho (MÉDA, 1998), oculta a questão camponesa admitindo que a evolução inevitável da história é a da industrialização da sociedade.

Apesar disso, podemos observar a persistência de formas originais de trabalho junto a certos agricultorescamponeses que encontramos hoje, entre outros, nos movimentos associativos do Grande Oeste como a Organização da Agricultura Sustentável.

As premissas dessa organização são relativamente antigas. Podemos situá-las no decurso dos anos 70 (criação do Sindicato de Camponeses-Trabalhadores em 1974), com as primeiras práticas da co-gestão e emergência ao núcleo da esquerda cristã de movimentos explicitamente autogestionáveis (PSU, CFT, extrema esquerda, correntes regionalistas etc.). No início, a idéia era de colocar em contato os camponeses e os atores ligados pelo desenvolvimento sustentável, a fim de facilitar o acesso ao conhecimento e à divisão de experiências no domínio do desenvolvimento, e de se associar federativamente a uma rede interdepartamental para trabalhar na consecução de uma agricultura "mais autônoma e mais econômica."5 Deste modo, o princípio que reúne esta organização advém de um modelo que tenta integrar as preocupações sociais, éticas, ecológicas, econômicas etc. Nesse sentido, a alternativa proposta não é unidimensional como tantas outras formas de agricultura não produtivistas, que se qualificam prioritariamente pelas escolhas técnicas (agricultura biológica, certificada etc.).

Em junho de 1994, grupos de desenvolvimento existentes no Oeste criam uma estrutura informal: GOAD (Grupos Oeste de Agricultura sustentável) que se tornaram em

1 Federação nacional de sindicatos de agricultores e centro nacional de jovens agricultores.

2 Segundo Tchayanov (1990), cujos trabalhos datam dos anos 20 , na produção camponesa, o trabalho é realizado pelos membros da famnia, mas a produção não se reduz a uma unidade econômica de subsistência: ela produz mais, ela vende os produtos, ela é ligada à produção comercial. É isso que permite à família viver e se reproduzir. Acrescente-se ainda que, os camponeses têm as práticas d'échange-don, ou seja, de economia não monetária.

3 Cf. em particular sua obra Resistências Camponesas, publicada em 1992.

4 Cf. Les Champs du départ, no qual eles são interessados nos agricultores ditos intermedírios - que encontramos hoje ainda no seio da Confederação Camponesa - e que "nem verdadeiramente tradicionais, nem verdadeiramente inovadores, colocam em prática em sua produção combinações produtivas tão boas quanto originais".

5 Para retomar a fórmula proposta desde 1978 por Jacques Poly, à época Diretor Geral do Inra. 
1997 RAD (Rede Agricultura Sustentável). Este último é uma expressão inter-regional dos CIVAM. ${ }^{6}$ Ele foi formado sob a égide de líderes da comissão de meio ambiente da FN-CIVAM (Federação nacional dos CIVAM) à qual ele é filiado. No verão de 1999 , os grupos que formam o RAD são em número de $22,{ }^{7}$ e este último reagrupa hoje mil agricultores que, na sua imensa maioria, pratica a policultura-criação de animais. Os grupos pioneiros são o Cedapa (Centro de estudos para um desenvolvimento agrícola mais autônomo), criado em 1982 e o Aldis (Ação local para um desenvolvimento internacional mais solidário), em 1984. A dinâmica que impulsionou estes dois grupos apoiou-se principalmente no importante papel desempenhado por seus líderes: saber empírico e experiência prática conjugada com a ação militante. ${ }^{8}$ Depois dos grupos pioneiros constituídos entre 1982 e 1986, grupos novos são criados, a partir de 1990 , graças a uma influência vinda de fora (provinda do Cedapa principalmente), mas também seguida de visitas de agricultores, de sessões de formação sobre a desintensificação (da agricultura convencional) ${ }^{9}$ ou sobre o desenvolvimento etc.

Assim, hoje, existe com o RAD, principalmente, uma racionalidade campesina e de formas de trabalho associados que resistiram à industrialização da agricultura. Por que estas formas de trabalho camponês resistiram? Qual é sua especificidade? Em que diferem elas do trabalho de "empresário e agricultores", conforme Marcel Gauchet (GAUCHET, 1990)? Poderão elas responder às crises que perpassam nossa sociedade?

Partindo das motivações invocadas pelos atores em questão ${ }^{10}$ e seus fundamentos teóricos, vamos tentar mostrar que, se formas originais de trabalho camponês se mantêm, isso ocorre porque elas respondem a uma interrogação de seus promotores sobre o sentido de sua atividade, elas são o fruto de um pensamento complexo, e o interesse que elas suscitam hoje na França, no âmbito institucional e no seio da sociedade civil se explica pela sua capacidade de responder às profun- das crises social e ecológica que afetam as sociedades ocidentais.

\section{Uma atividade agrícola de multiplas funções versus divisão do trabalho e especialização}

\section{A heteronomia como forma de desumanização}

Entre os agricultores que combinam a cultura e a criação em agricultura produtivista, não existe ou ocorre pouca complementação entre os diversos setores que são especialisados. ${ }^{11}$ Opera-se então uma divisão do trabalho na agricultura, o que se torna possível pela divisão de tarefas na exploração, acentuada por aquelas das indústrias a montante e a jusante do aparelho de enquadramento sindical, administrativo etc. Dessa forma,

para existir e para durar, uma empresa industrial (...) tem necessidade de calcular os fatores relacionados com a racionalidade econômica de sua gestão. E estes fatores não estão somente restritos ao funcionamento interno mas dependem igualmente de condições externas, ou seja, determinadas pelo meio político, jurídico, administrativo, cultural (GORZ, 1988, p. 47).

Como no conjunto da sociedade capitalista, existem então duas formas de divisão de trabalho na agricultura, uma divisão tayloriana de tarefas na escala de produção (permitida pela moto-mecanização, a utilização de produtos químicos, as tecnologias genéticas, a revolução informática etc.), e uma divisão macrossocial, que corresponde "à explosão da produção em atividades produtivas que só valem quando em combinação com outras" (GORZ, 1988, p. 76), ao longo da cadeia produtiva e segundo um nível mínimo de enquadramento técnico.

6 Os Civam (Centros de iniciativas para a valorização da agricultura no meio rural) são associações, lei 1901 , criadas nos anos 60 , as quais têm um papel de formação, de orientação e de apoio às iniciativas locais no meio rural. Elas tinham, no início, um papel de ensino e divulgação.

7 Estes grupos estão situados principalmente no Oeste da França (regiões Poitou-Charentes, Bretagne et basse-Normandie). Três dentre eles estão fora desta área geográfica (Corrèze, Meurthe-et Moselle, Alpes-Maritimes).

8 Cf. os percursos de Andrée Pochon, co-fundador do Cedapa em Côtes-d`Armor, autor de Champs du possible. Plaidoyer pour une agriculture durable, e de Jean-

Yves Griot, produtor de leite en Mayenne du RAD.

$9 \quad$ Nota do tradutor.

10 Nessa ocorrência, 44 criadores tinham práticas de agricultura do tipo produtivista e do tipo sustentável. Estes últimos foram entrevistados entre abril de 1998 e maio de 1999 nas regiões Poitou-Charentes. Bretagne e basse-Normandie.

11 Entre os produtores de cereal, a especialização é ainda mais desenvolvida, pois os animais foram suprimidos. 
Esta divisão de trabalho é ainda visível hoje na maior parte dos Departamentos de Agricultura, que são organizados de maneira piramidal com uma co-direção Estado-profissão, serviços gerais (estatísticas, estudos), serviços de coordenação, assegurando a coerência das ações de desenvolvimento e, os serviços de intervenção especializados (conselhos ou estudos em grandes culturas, em criação, em matéria jurídica e fiscal, em economia e gestão de exploração agrícola etc.). ${ }^{12}$

A divisão tayloriana das tarefas permanece, atualmente, mais ou menos parcial nas produções agrícolas, mesmo entre as mais modernizadas. De fato, apesar da artificialização desenvolvida do ser vivo, o instrumento de trabalho dos agricultores permanece - porque ele está vivo - heterogênio; sua divisão completa torna-se difícil. Selecionados por sua produtividade, seu teor em proteínas ou sua taxa de gordura etc., os animais e as plantas também não têm seu funcionamento ainda totalmente controlados. ${ }^{13}$ Esta divisão é, ao contrário, muito mais avançada montante e a jusante, em que uma verdadeira industrialização é possível porque o material trabalhado não é , ou não é mais ser vivo (por exemplo, o trabalho em cadeia nas unidades de primeira transformação e de condicionamento de aves.

Acrescenta-se à divisão tayloriana do trabalho, sua divisão macrossocial. Esta última se acentuou com o desenvolvimento de cadeias de produção cada vez mais estruturadas, ${ }^{14}$ o papel e o impacto do aparelho técnicoeconômico de enquadramento tem diminuído consideravelmente nos dias atuais. ${ }^{15}$ Ao empobrecimento da cultura técnica e econômica experiencial dos agricultores que, engajados na modernização dos anos 60-70 eram seguidos pelos conselheiros, soma-se hoje uma verdadeira desumanização ${ }^{16}$ da essência de seu trabalho. De fato, como ressalta Andre Gorz, a propósito da divisão do trabalho na indústria, a quantidade de saber tecnológico incorporado ao produto alimentar industrial ultrapassa largamente, hoje, as capacidades de um único indivíduo (GORZ, 1988, p. 76).

$\mathrm{O}$ paradigma da agricultura produtivista funciona então na esfera da heteronomia" "em meio a qual a natureza e o conteúdo das tarefas assim como suas relações são heterodeterminadas de maneira a fazer funcionar os indivíduos e grupos complexos como as engrenagens de uma grande máquina" (GORZ, 1988, p. 49) No setor agrícola, a grande máquina é o complexo agroindustrial, o pessoal é composto dos empregados desse complexo e dos agricultores que adotaram as práticas do tipo industrial em suas produções.

\section{Heteronomia como recurso de reprodução a serviço da autonomia}

Para os agricultores da Rede de Agricultura Sustentável, "a agricultura sustentável é antes de tudo uma agricultura autônoma e econômica". ${ }^{18} \mathrm{O}$ que é autonomia? Os agricultores que a defendem recusam portanto a heteronomia? Podemos articular autonomia e hetero-nomia?

Entre os agricultores do RAD, o desejo de autonomia corresponde a uma vontade de controlar sua própria atividade no seio da produção, ou seja, de poder fixar as diretrizes de funcionamento dentro de regras elaboradas coletivamente em diferentes níveis (local, RAD, nacional, União européia...). Para atingir esse objetivo, eles recusam uma divisão e uma especialização extrema de sua produção e fora dela. Dessa forma, eles escolhem apreender o funcionamento de sua produção de maneira global e sistêmica.

12 A evoluçāo do contexto social e as expectativas sociais em matéria de meio ambiente fazem, entretanto, emergir novos serviços transversais (diversificação, meio ambiente e organização), no seio dos quais se opera uma recomposição de funçōes e de temáticas.

13 Porém. podemos nos perguntar se a clonagem de animais, privada a sua criação de condiçōes naturais, não anuncia o início do controle total da natureza pelo homem...

14 Esta estruturação tem, por exemplo, dado início às produçōes integradas. Os agricultores em integração não são mais que um elo da cadeia. Em produção de suínos, por exemplo, certos agricultores têm a única tarefa de engordar os animais - com produtos concentrados industrialmente, dos quais eles não conhecem a composição -, leitões nascidos em outro lugar, abatidos em série, transformados e depois vendidos em hipermercados para consumidores anônimos.

15 Segundo palavras de certos agricultores produtivistas, entrevistados no departamento de Deux-Sèvres entre abril e junho de 1998.

16 Estas sociopatologias ligadas a políticas de iniciativas do Estado e das organizaçōes agrícolas para modernizar a agricultura francesa foram estudadas em particular por Michèle Salmona (1994).

17 Segundo André Gorz, em toda sociedade moderna, a hétero-regulação se faz a um só tempo pelo mercado (hétero-regulação espontânea) e pelos aparelhos institucionais, ou seja, o Estado (hétero-regulação programadi).

18 Autonomia e economia são, por outro lado, dois termos freqüentemente utilizados para indicar os grupos da rede: Cedapa (Centro de estudos para um desenvolvimento agrícola mais econômico e mais autônomo). 
Esta escolha não é marcada por uma recusa do sistema controlador-profissional, mas por sua influência alienante. Para limitá-la, os agricultores se organizam em redes: entre elas (RAD), com o meio associativo não agrícola (rede Coerência) ${ }^{19}$ com o Estado e as coletividades locais, com o meio profissional agrícola convencional. A idéia da organização é de criar uma relação social não hierarquizada, permitindo a cada um usufruir de uma certa forma de autonomia. Estes agricultores reivindicam assim serem atores responsáveis: "Eu me aborreço quando um técnico vem me dizer o que eu devo fazer. No Civan do Haut Bocage, ${ }^{20}$ nós nos relacionamos, mas não há hierarquia, e nós desejamos que os intercâmbios com outras estruturas como 'a Câmara' se façam dentro do mesmo espírito."

Eles não recusam mais o comércio, ${ }^{21}$ porque eles não valorizam um modo de produção do tipo autárquico. ${ }^{22}$ Simplesmente, como o explicam os autores de Champs du départ, a propósito dos chamados intermediários: "Se eles comercializam o essencial de sua produção, eles não produzem para o mercado propriamente dito mas o fazem para reproduzir sua exploração e sustentar as necessidades de sua família, recorrendo assim ao mercado "como meio de reprodução" (ALPHANDÉRY; BITOUN; DUPONT, 1989, p. 10).

Finalmente, os agricultores do RAD revelam um desenvolvimento sem limites do sistema agroindustrial e a burocratização excessiva do sistema profissional-estatal que reduzem sua autonomia e engendram aquilo que Ivan Illich chamou "contraprodutividade": a agricultura não pode mais alimentar os homens (vacas loucas, frango com dioxina etc.) ainda que seja sua função primeira; ela deteriora o território em lugar de preservar e de o administrar (águas com nitrato, banalização das paisagens etc.); ela origina mais desemprego do que empregos; ela desumaniza em lugar de criar relações sociais etc.
A divisão macrossocial do trabalho tal qual ela existe é assim, em si mesma, um freio ao desenvolvimento da agricultura sustentável. A hipertrofia do mercado e do aparelho burocrático de enquadramento (da formação, da instalação, da evolução da produção, da aposentadoria etc.) do agricultor conduz a sua perda de autonomia.

Em conseqüência, estes agricultores recusam a racionalidade da esfera heteroregulada da megamáquina industrial-estatal. Em sua racionalidade própria, a hetronomia deve estar a serviço da autonomia. E a razão pela qual eles dão uma certa importância à realização de circuitos curtos de comercialização (venda na fazenda, mercados rurais ${ }^{23}$ ), cadeias de produção sem oGM, ${ }^{24}$ traços específicos de modos de produção resultam da agricultura sustentável. ${ }^{25}$ Isto lhes permite manter sua autonomia sem se submeter às praticas autárquicas.

\section{Autonomia por ser mais econômico}

O desejo de autonomia é indissociável da vontade de promover uma atividade econômica (economia de "entradas" através da redução de dosagem, da prática de rotação de mais longa duração, da reintrodução de pastos permanentes etc.) Esta preocupação "de economia" ressalta uma racionalidade totalmente diferente daquela existente na agricultura produtivista. Com efeito, no paradigma desta última, a racionalidade dominante é fundada na teoria econômica neoclássica, na qual o empregador produz para satisfazer acumulação ilimitada. No paradigma da agricultura sustentável, a lógica econômica do esforço ilimitado é substituída por aquela, fundamentalmente cultural, podemos dizer existencial, da necessidade limitada, do suficiente.

19 Coherência é um conjunto de associações de camponeses, de consumidores, de protetores da natureza e da saúde trabalhando para o desenvolvimento sustentável no Oeste.

20 O Civam do Haut Bocage, situado ao noroeste de Deux-Sèvres, é um dos grupos do RAD.

21 Estes agricultores comercializam como os outros seus produtos que saem da unidade de produção.

22 Definimos aqui autarquia como uma prática essencialmente econômica que visa a assegurar ou preservar o indivíduo, as condições de sua independência e de sua liberdade em tudo que implica sua produção e reprodução natural.

23 Em 1995, seis produtores, dos quais dois estão ligados a um dos grupos do RAD (Civam do Haut Bocage em Deux Sèvres), decidiram criar um ponto de venda coletiva de seus produtos (carne, laticínios), la Ferme des Bois. Esta última faz parte da Associação nacional para a venda coletiva (Avec).

24 Uma cadeia de comercialização de soja sem OGM está em vias de se concretizar entre os agricultores do RAD e os produtores de soja do estado do Rio Grande do Sul, no Brasil, através das cooperativas La Cana, la CAM (Mayenne) e a Cooperativa dos agricultores da Bretagne.

25 Uma marca "Agricultura sustentável" foi confiada ao Instituto nacional da propriedade industrial em 1999 por valorizar a produção realizada nos moldes mais condizentes à preservação do meio ambiente. 


\section{Agricultores inseridos na sociedade e abertos para o mundo: cultura do "fazer eu mesmo" versus competência técnica profissional}

\section{A cultura e a imaginação contra a rotina}

Segundo os agricultores do RAD, a autonomia releva ao mesmo tempo sua vontade de poder organizar o desenvolvimento de suas atividades e de perseguir livremente um objetivo a que eles mesmos se propuseram. Ser autônomo é, finalmente, poder desenvolver-se humanamente, ou seja, liberar-se no seu trabalho e se liberar do trabalho.

Deste modo, liberar-se do trabalho significa trabalhar na produção. Os agricultores do RAD explicam que a agricultura sustentável permite uma simplificação do trabalho: "Minha motivação (para mudar o sistema) era de colocar em prática um sistema forageiro, baseado em uma rotação com o milho ensilagem e rotações curtas; era preciso revirar a terra todos os anos. Atualmente, os campos duram 6 a 7 anos, assim, o trabalho é simplificado".

Esta simplificação dá ensejo a uma limitação de trabalhos repetitivos: por exemplo, em lugar de ressemear um campo a cada 18 meses, eles preferem implantar um campo de longa duração " e vê-lo brotar, cuidar, adaptar as operações culturais para realizar em função de seu estado e de sua evolução, também para se criar um pouco de imprevisto e de invenção cada dia". Esta simplificação da qual falam os agricultores do RAD não pode ser traduzida como uma estandartização simplificadora de tarefas. Ela é, ao contrário, uma construção intelectual do trabalho cotidiano, um vai-e-vem entre o exercício do corpo e do espírito em busca de uma harmonia entre o trabalho físico e o trabalho intelectual.

Esta construção constitui uma "obra" porque ela produz qualquer coisa de original, de artesanal, de único, e que pode se transmitir de uma geração a outra. ${ }^{26}$ Assim, os agricultores do RAD "produzem uma obra" no sentido arendtiano do termo: eles produzem bens cujo valor é estético e sustentável.

No Civam do "Haut Bocage", a árvore e a cerca viva fazem parte destas obras. Eles são assim qualifica- dos pelo camponês-orientador dos projetos de gestão de cerca viva ${ }^{27}$ "de vetor ou de porta de entrada para dar uma idéia de quantidade no conjunto da paisagem". A cerca é também o "símbolo dos limites dos campos do futuro e dos campos do passado". A colocação em prática do plano de gestão de cercas constitui para este camponês um bom instrumento " para restaurar uma construção antiga ("le Bocage"), e para que a questão das árvores e da cerca não redunde em uma obrigação para o camponês, pois a árvore há muito tempo foi (e é ainda) o feito do príncipe ("le fait du Prince"), e um meio para "que hoje, com o avanço da democracia, os camponeses tenham comportamento liberado em relação à arvore e que recusem a sujeição aos príncipes dos tempos modernos". Além de seu papel na preservação da biodiversidade, a cerca viva representa aqui um espaço cultural que advém da sensibilidade, e da psyché de cada um. Nesse sentido, ela é a materialização de percepções imateriais, de qualquer forma, uma obra de arte em que o camponês é ao mesmo tempo criador e contemplador.

A noção do trabalho entre os agricultores do RAD se contrapõe, assim, àquelas dos produtivistas que, em razão de sua visão estreita da rentabilidade de sua produção, fazem da agricultura um ofício, uma profissão e não um modo de vida. Consideram o trabalho como a atividade fundamental do homem, a atividade através da qual se desenvolvem, estes agricultores só se realizam através do trabalho. Dessa forma, supervalorizando o trabalho, eles esquecem as outras atividades humanas e se enredam numa reprodução incessante de uma atividade efêmera e alienante (ARENDT, 1994).

Desse modo, nesse paradigma da agricultura produtivista trabalhar é produzir riquezas econômicas em nome de um sucesso material que passa pela exaltação de tudo que tem um valor mercantil e necessita, assim, o acesso a retornos financeiros consequientes pela escolha de orientação produtiva permitindo: "Eu escolho minhas produções por vontade de obter um retorno máximo sobre a produção, pelo bem-estar e o saber viver ${ }^{28}$ dos produtores".

Arraigados em uma cultura de consumo, os agricultores, pela apologia única do trabalho - no sentido que lhe dá Hannah Arendt -, estão presos na engrenagem da reprodução de uma vida perpetuamente agoni-

26 Um conjunto de normas relativas à agricultura sustentável foi acertada pelo Cedapa em Côtes d’Armor. Ele propõe dispositivos suficientemente fáceis de modo a que qualquer pessoa os possa adaptar a sua situação utilizando sua criatividade.

27 Neste grupo, os agricultores colocaram em prática um programa de restauração de cercas vivas no espaço de produção.

28 O bem-estar e o saber viver correspondem aqui a um acesso a todo conforto material: carro, ar condicionado etc. 
zante. Eles vivenciam, em consequiência, a necessidade de renovar o trabalho sem cessar - o que lhes parece normal. Preso nesse ciclo de reprodução infinita do trabalho, alguns deles explicam não haver necessidade de atividades outras, não diretamente ligadas ao trabalho com sua produção, ou de tirar muitas férias. ${ }^{29}$ "Faz longo tempo que eu não tiro férias; eu estou habituado a viver assim. Eu não sinto necessidade de interromper a produção".

Liberar-se do trabalho significa aproveitar o tempo para fazer outra atividade. Desta forma, os agricultores do RAD ressaltam que a passagem do sistema de produção intensiva aos sistemas de produção sustentável lhes permite trabalhar diferentemente sua produção e, assim, liberar o tempo para investir em atividades distintas, ligadas ou não a sua atividade de agricultor. Muitos são aqueles que trabalham fins de semanas alternados (aqueles que estão em GAEC - agrupamento agrícola de produção em comum - em particular), e têm de uma a quatro semanas de férias por ano.

O tempo livre lhes permite, assim, voltar-se para a sociedade através de diversas atividades: militantes, artísticas, culturais etc.

Atividades militantes:

- militantismo sindical: muitos agricultores do RAD fazem parte da Confederação Camponesa. Esta adesão constitui, para eles, não somente um meio de defender seus interesses enquanto agricultores, mas também uma maneira de refletir sobre seu lugar, seu papel na sociedade dentro de uma perspectiva não corporativista, mas de cidadão. (as atividades da Confederação camponesa: participação no ATTAC, ${ }^{30}$ por exemplo).

- militantismo político: no meio dos partidos políticos (numerosos agricultores da rede são próximos ou ligados aos Verts) ou no meio associativo (adesão à rede Cohérence, à Eaux et Rivières de Bretagne, à SEPNB etc.). ${ }^{31}$
- militantismo espiritual: muitos dos agricultores do RAD militaram no MRJC (Movimento Rural da Juventude Cristã) e participam hoje da CMR (Cristãos do Mundo Rural), em diversas associações, cristãs ou não, em vocações humanitárias: CCFD (Comitê Católico Contra a Fome), associações de ajuda aos deficientes, pessoas idosas, abrigo para os SDF etc. que são para eles os vetores de abertura para o exterior: "É (o CCFD) para nós uma incrível abertura porque isto nos permite receber os brasileiros, os malgaches e os cambodgianos. $\mathrm{E}$ no ano passado, partimos ao Perú para encontrar pessoas que preparam projetos no meio rural".

Atividades artísticas, culturais e de entretenimento:

Alguns aprendem música (acordeom, violino, piano) ou participam de um coral; outros fazem dança, teatro.

A maior parte lê revistas (Alternativas econômicas, Políticas, Correio internacional, O Mundo diplomático, Povos solidários, Terra dos homens, Testemunha cristã, Campanhas solidárias, Trans-Rural-Iniciativas, Silêncio, O correio do meio-ambiente do INRA) tratando de temáticas transversais e de grandes questões da sociedade. Esta abertura para o mundo e para pluralidade forma uma elite intelectual do mundo camponês. Alguns aprendem línguas estrangeiras (inglês, espanhol, russa etc.) para receber turistas de passagem ou para viajar: "Viajar para nós é vital. Temos realmente necessidade de contatos fora de nossa produção". Muitos fazem parte de associações culturais locais como o Galbob. ${ }^{32}$

Eles têm atividades esportivas: basquete, futebol, pesca, passeios (a pé, de bicicleta) etc.

Escolhendo praticar atividades tão variadas, os agricultores do RAD demonstram sua vontade de inserção na sociedade e de abertura para o mundo. Para eles, "trabalhar não é somente produzir riquezas econômicas; é também uma maneira de se produzir" (GORZ, 1988, p. 105). Trabalhar é, então, criar e dar sentido a sua ativida-

\footnotetext{
29 Seguramente, em nossa sociedade, as férias tornam-se cada vez mais um objeto de consumação controlada e orientada. Todavia, no espírito dos agricultores entrevistados, o termo férias exprime mais uma aspiração de viver o tempo livre, não sujeito à rotina de obrigações do trabalho cotidiano.

30 A associação para uma taxação de transações financeiras de ajuda aos cidadãos, criada em 1998, trabalha contra as lógicas financeiras destrutivas do liberalismo, propondo soluções alternativas.

31 Sociedade para o estudo e a proteção da natureza na Bretagne.

32 O principal grupo de animação do Centro-Oeste da Bretagne se interessa pela questão da memória, de línguas regionais e do patrimônio.
} 
de, e a sua vida. Mas a questão do sentido seria reservada à agricultura sustentável ou poderia a agricultura produtivista também comportar esse sentido?

\section{Crítica da tecnização da sociedade e da artificialização do mundo}

A concepção do trabalho na agricultura produtivista está em sua divisão e sua especialização autorizada por uma tecnização crescente e uma artificialização do ser vivo. Desde os anos 50, às revoluções moto-mecânica e química são acrescentadas as revoluções informáticas e biotecnológica, cuja " reunião em um complexo tecnológico único deixa prever uma nova era da produção alimentícia, divorciada da relação com terra, clima, ciclo de estações, todos fatores que condicionaram há longo tempo os rendimentos agrícolas" (RIFKIN, 1996, p. 173).

Atualmente, na França, nós estamos ainda longe da era das fazendas-usinas, totalmente automatizadas e do fim da agricultura em pleno ar, previstas por Jeremy Rifkin. Mas devemos chegar lá? Devemos desejar o desenvolvimento de um modelo de produção como esse? Devemos continuar a sustentar uma revolução biotecno-lógica sem proteção à agricultura? É preciso que na França os agricultores não sejam mais que profissionais da cultura do milho ou da criação de frango em série? A hipertecnização poderá resignificar ao ofício de agricultor que atualmente, com as crises sanitárias frequientes (vaca louca, dioxina etc.) perdeu sua essência? Será necessário finalmente transformar os agricultores em supertécnicos do ser vivente?

É o que sustentam os promotores da agricultura produtivista, valorizando a tecnização do ofício e a profissionalização que a acompanha. Liberar completamente o agricultor das restrições inerentes a sua atividade (o clima, os solos etc.), é com certeza o projeto da agricultura "moderna" do amanhã.

Os agricultores produtivistas podem fazer uso de sua capacidade reflexiva na sua atividade se sua única "cultura" é uma cultura técnica? Se a tecnizaçao da agricultura pode acrescentar a eficácia do trabalho, reduzindo a duração e sua dificuldade, "o grande domínio da técnica (...) diminui o campo da experiência sensível e da autonomia existencial; ela separa o produtor do produto ao ponto dele não mais conhecer a finalidade do que ele faz" (GORZ, 1988, p. 115). Praticando uma agricultura baseada somente na ciência e na técnica, os agricultores produtivistas reduzem sua capacidade reflexiva e o sentido que eles dão a seu trabalho. Por outro lado, a agricultura que eles praticam perde uma parte de seu significado porque "para uma cultura profissional que se separa do mundo vivido na dimensão sensível corres-ponde(...) a produção de um mundo sem valor sensível, e a esse mundo uma sensibilidade endurecida e que enrijece em conseqüência o pensamento" (GORZ, 1988, p. 113-114).

Não é mediante a tecnização sem limites da agricultura que vamos restituir o sentido ${ }^{33}$ à atividade de produção agrícola. Por outro lado, não é assim que resolveremos a crise essencialmente política e ética que ela atravessa. É por tudo isso que os agricultores do RAD, sem recusar a tecnologia, propõem criar uma nova ética à altura dos perigos potenciais de nossa civilização tecno-científica, embasando-se em uma construção de um princípio de responsabilidade (JONAS, 1979). Eles articulam ainda sua atividade de produção com outras atividades e se instalam, com frequiência, seja em outro setor (formação, animação, saúde etc.), após uma experiência profissional, ou após realizar estágios e viagens ao estrangeiro etc. Esse percurso, necessário ao "amadurecimento" de seus projetos de vida, é específico deles. ${ }^{34} \mathrm{~A}$ agricultura sustentável ultrapassa então o quadro técnico-econômico de produção: para permanecer, a agricultura deverá se fundamentar em um projeto para quem a pratica e para a sociedade como um todo.

\section{Para as geracões futuras: restabelecer relações com a natureza e criar empregos}

Ultrapassar a crise do sentido, a crise ecológica e a crise do emprego

À crise do sentido que conhece a agricultura produtivista se somam as crises ecológicas (poluição

33 Os sintomas da crise "existencial" dos agricultores produtivistas são numerosos: dívidas, estresse, falências, suicídios etc. Eles foram objeto de estudo de François Colson a partir dos anos 1985.

34 Os agricultores produtivistas entrevistados têm um período de pré-instalação bem profissional: BTA ou BTSA, ajuda-familiar durante um ou dois anos, seguido de estágio de seis meses em via da instalação. 
das águas, erosão dos solos, deterioração dos habitats etc.) e sociais (êxodo agrícola, dificuldades de reclassificação em caso de falência, desertificação, isolamento, envelhecimento da população etc.).

Os resultados econômicos permitidos pela divisão e a especialização do trabalho, dos quais falam os agricultores produtivistas, são totalmente relativos. Se a rentabilidade econômica individual é por vezes efetiva, a rentabilidade econômica "coletiva" não o é porque certos custos são externalizados: no Oeste da França, primeiro os custos ecológicos ligados a culturas como a do milho e a algumas condutas de criação como a de porco(...); em seguida, os custos sociais resultantes do crescimento e da concentração das produções.

Estes custos ecológicos e sociais, perceptíveis no âmbito de uma região têm, na realidade, uma dimensão planetária: "As recentes descobertas tecnológicas na agricultura mundial anunciam um aumento de produtividade $\mathrm{e}$ uma diminuição de necessidade de mão-de-obra que nenhuma outra revolução tecnológica na história do mundo jamais suscitou. O preço humano do progresso econômico será sem dúvida surpreendente. Para centenas de milhões de camponeses do mundo inteiro, é o horizonte de sua eliminação definitiva do processo econômico que avança. Sua marginalização poderia levar, no século próximo, a um cataclismo social planetário" (RIFKIN, 1996, p. 178-179).

\section{A agricultura "sustentável" poderá responder a estas crises?}

Em razão da crise, todo mundo reconhece hoje os efeitos negativos, sobre o ecossistema, de algumas práticas como a cultura do milho ou a arrancada intempestiva de cercas vivas. $O$ desenvolvimento de sistemas de produção autônomos e econômicos aparece assim como uma via interessante para limitar esses efeitos.

Parece evidente nos dias de hoje que uma certa autonomia da produção agrícola pode permitir a obtenção de níveis de atuação econômica mais elevados. Todavia, além do peso dos lobbies, a autonomia que reivindicam estes sistemas de produção é uma ameaça, pois é a demonstração de que a abertura máxima ao mercado nem sempre é a via mais eficaz. Ora, colocar em questão um esquema de pensamento que postula que o aumento de troca de mercadorias traz necessariamente o bem estar coletivo é um ato subversivo (KROLL, 1998, p. 7).

Como o discurso econômico dominante é de natureza liberal e trabalha essencialmente em termos de cadeia, ${ }^{35}$ é difícil hoje de avaliar o impacto da agricultura sustentável sobre o emprego, em particular em escala de território. De toda forma, os problemas que se colocam àqueles que praticam este tipo de agricultura dizem respeito mais às questões de sociedade em matéria de emprego (divisão do trabalho, economia solidária etc.) do que àquelas com que se defrontam os agricultores "produtivistas"(competição, rentabilidade econômica individual etc.).

\section{Trabalhar por uma sociedade solidária}

Os agricultores do RAD abrem um caminho em direção a uma sociedade solidária (ILLICH, 1973).

Eles reivindicam, de fato, uma certa forma de autonomia em seu trabalho, em particular, uma autonomia de decisão possibilitada por uma otimização do aparelho profissional-estatal e do mercado.

Esta autonomia lhes dá a possibilidade de exercer sua criatividade. Assim, eles inventam, a partir de algo existente (um meio físico e biológico, uma situação familiar) e respeitando certas regras elaboradas coletivamente (normas do RAD por exemplo), seu modo de produção e de organização do trabalho. Este desejo de trabalhar se torna possível graças as suas grandes capacidades de imaginação que repousam em parte, sobre sua integração na sociedade e sua abertura sobre o mundo sensível através dos engajamentos associativos civis, culturais e políticos não corporativistas. Eles se inserem nas redes de iniciativas densas e complexas (colocar em rede intra, intra-associativa e interassociações-instituiçõs) onde existem formas de trocas de habilidades - entre os agricultores, assim como entre os agricultores e outros atores da sociedade - e de formas de

35 Os estudos de cadeias não levam em conta, por exemplo, os empregos perdidos em seguida ao fechamento de escolas, ao desaparecimento de pequenos comércios etc. 
economia solidária ${ }^{36}$ (utilização do mercado como meio de reprodução). Geralmente, é claro que os agricultores sustentáveis se inscrevem no âmbito antiutilitarista.

\section{REFERÊNCIAS}

ALPHANDÉRIE, P. B. P.; DUPONT, Y. Les Champs $d u$ départ. Une France rurale sans paysans? La Découverte. Paris: [s. n.], 1989.

ARENDT, H. Condition de l'homme moderne, Calmann-Lévy. Paris: Collection Agora, (1961) 1994.

DE CRISENOY, C. Lénine face aux moujiks. Paris: Seuil, 1978.

DUPONT, Y. Du déracinement des paysans au déracinement de la vie. Sous l'amour des hommes, la peur de la nature et du hasard. Caen, 1994. Thèse (d'habilitation) - Université de Caen.

GAUCHET, M. Pleurer les paysans? Le Débat, n. 60, 1990.

GORZ, A. Métamorphoses du travail. Quête du sens. Critique de la raison économique. Paris: Galilée, 1998.

ILLICH, I. La Convivialité. Paris: Points-Seuil, 1973.

JONAS, H. Le principe Responsabilité. Une éthique pour la civilization technologique. Paris: Cerf, 1990.
Redefinindo o trabalho como uma atividade autônoma, criativa etc., em síntese, portadora de sentido, os agricultores do RAD participam, assim, também da construção de uma sociedade pós-moderna solidária, em uma ruralidade cidadã e viva.

KROLL, J. C. L'activité économuique, c'est produire, répartir, consommer. In: COLLOQUE L'AGRICULTURE, UNE CHANCE POUR L'EMPLOI, 1998, Nantes. Actes... Nantes: Editions Siloë, 1998.

LAVILLE, J. L. Entre marché et État, faire naître une économie solidaire. La Revue du MAUSS, n. 3, jan./juin 1994.

MÉDA, D. Le Travail, une valeur en voie de disparition. $\mathrm{Pa}-$ ris: Champs-Flammarion, (1995) 1998.

PERNET, F. Résistances paysannes. Grenoble: Presses universitaires de Grenoble, 1992.

RIFKIN, J. La fin du travail. Paris: La Découverte, 1996.

SALMONA, M. Souffrances et résistances des paysans français. Paris: L'Harmattan, 1994.

TCHAYANOV, A. l'Organisation de l'économie paysanne. Paris: Librairie du Regard, 1990. 